\title{
QUALIDADE SANITÁRIA E FISIOLÓGICA DE SEMENTES DE PINHÃO MANSO TRATADAS COM FUNGICIDAS
}

\section{L.R. Venturoso ${ }^{1}$, A.L.F. Lourenção ${ }^{2}$, C.R. Pezarico ${ }^{3}$, W.L. Gavassoni ${ }^{1}$, L.M.A. Bacchi ${ }^{1}$}

1 Universidade Federal da Grande Dourados, Faculdade de Ciências Agrárias, Laboratório de Fitopatologia, CP 533, CEP 79804-970, Dourados, MS, Brasil. E-mail: luck_rv@hotmail.com

\section{RESUMO}

Foram desenvolvidos dois experimentos na Universidade Federal da Grande Dourados, com o objetivo de avaliar a eficiência dos fungicidas, Carboxin + Thiram e Carbendazin + Thiram, em diferentes doses, na sanidade de sementes e seu efeito sobre o vigor de plântulas. Os fungicidas, Carboxin + Thiram foi avaliado nas doses de 350, 450 e $550 \mathrm{~mL}$ e Carbendazin + Thiram nas doses de 200,300 e $400 \mathrm{~mL}$, sendo as respectivas doses para $100 \mathrm{~kg}$ de sementes. Odelineamento experimental para ambos os ensaios foi inteiramente casualizado com 7 tratamentos, 10 repetições para o ensaio de sanidade e 5 repetições para análise do vigor. Analisaram-se a porcentagem de incidência de fungos nas sementes e o vigor de plântulas, por meio da emergência a campo, índice de velocidade de emergência e altura de plantas. Relata-se a incidência de Aspergillus sp., Penicillium sp., Fusarium sp., Phomopsis sp. e Rhizopus sp., sendo Carboxin + Thiram na dose de $550 \mathrm{~mL}$, o tratamento mais eficiente no controle dos patógenos. Quanto à emergência a campo, ambos os fungicidas foram eficientes, proporcionando aumentos que variaram de 48,9 a 97,4\% de emergência. O índice de velocidade de emergência foi favorecido pelos tratamentos com Carboxin + Thiram na dose de $550 \mathrm{~mL}$ e Carbendazin + Thiram nas doses de 300 e $400 \mathrm{ml}$. Constatou-se que Fusarium sp. foi o patógeno com maior percentual de incidência sobre as sementes, todavia, as maiores correlações com a baixa emergência foram observadas pela presença dos fungos Penicillium sp. e Phomopsis sp.

PALAVRAS-CHAVE: Jatropha curcas, tratamento de sementes, Carboxin + Thiram, Carbendazin + Thiram.

\section{ABSTRACT}

SANITARY AND PHYSIOLOGICAL QUALITY SEED OF JATROPHA TREATED WITH FUNGICIDES. Two experiments were conducted at the Federal University of Grande Dourados, in order to evaluate the efficiency of fungicides, Carboxin + Thiram and Carbendazin + Thiram at different doses on seed health and its effect on seedling vigor. The fungicides, Carboxin + Thiram was evaluated at doses of 350, 450 and $550 \mathrm{~mL}$ and Carbendazin + Thiram at doses of 200, 300 and $400 \mathrm{~mL}$, the respective doses for $100 \mathrm{~kg}$ of seeds. The experimental design for both trials was completely randomized design with 7 treatments, 10 repetitions for the test of sanity and 5 for analysis of the vigor. We analyzed the percentage incidence of fungi in seed and seedling vigor, through a field emergence, index of emergence speed and plant height. We report the incidence of Aspergillus sp., Penicillium sp., Fusarium sp. Phomopsis sp. and Rhizopus sp., and Carboxin + Thiram at a dose of $550 \mathrm{ml}$, the treatment most effective in controlling pathogens. For field emergence, both fungicides were effective, providing increases ranging from 48.9 to $97.4 \%$ of emergency. The index of emergence speed was favored by treatments with Carboxin + Thiram at a dose of 550 $\mathrm{mL}$ and Carbendazin + Thiram at doses of 300 and $400 \mathrm{ml}$. It was found that Fusarium sp. was the pathogen with the highest percentage of incidence on seeds, however, the highest correlation with the low emergence were observed by the presence of Penicillium sp. and Phomopsis sp.

KEY WORDS: Jatropha curcas, seed treatment, Carboxin + Thiram, Carbendazin + Thiram.

O pinhão manso (Jatropha curcas L.) é uma planta arbustiva da família das Euforbiáceas. Esta oleaginosa vem sendo considerada uma alternativa economicamente importante, devido ao seu alto teor de óleo e a sua qualidade (SATURNINo et al., 2005; PIEnIZ; SIlva, 2008), visando uma produção

${ }^{2}$ Fundação MS, Maracaju, MS, Brasil.

${ }^{3}$ Embrapa Agropecuária Oeste, Dourados, MS, Brasil. 
sustentável de biodiesel. Estes aspectos têm gerado grandes expectativas da espécie tornar-se uma opção agrícola rentável e passar a ser cultivada em larga escala no país.

Devido a sua rusticidade, a cultura adapta-se a condições edafoclimáticas muito variáveis, como regiões secas (Heller, 1996) e de baixa fertilidade (TEIXEIRA, 2005), e ocorrendo de forma natural no ambiente apresenta boa resistência a pragas e doenças. Segundo ARRUda et al. (2004), a cultura exerce um papel importante na proteção do solo, podendo ser cultivada em consórcio com outras culturas de importância econômica, melhorando o aproveitamento das áreas e auxiliando na fixação de mão-de-obra na zona rural pela geração de emprego e fornecimento de matéria-prima para a indústria.

O pinhão manso pode ser propagado por meio de estacas, semeadura direta no campo ou ainda por mudas. Esta última, por permitir melhores condições para o crescimento inicial da cultura, resulta em maior estabelecimento no campo. Independente do modo escolhido, ARRUdA et al. (2004) enfatizaram que a seleção das matrizes deve ser rigorosa e afirmaram ainda que as plantas oriundas de sementes são mais resistentes e de maior longevidade, atingindo idade produtiva após quatro anos, enquanto aquelas provenientes de estacas, apesar de começarem a produzir no segundo ano, são de vida mais curta e sistema radicular menos vigoroso.

A expansão da cultura do pinhão manso nos últimos anos, aliado ao limitado conhecimento técnico e científico sobre esta espécie, resultou na comercialização de sementes de forma "desordenada" e sem testes ou fiscalizações que atestem padrões mínimos de qualidade destinados à sua produção (Nevesetal., 2009a). SEVERINo et al. (2006) afirmaram ainda que a cultura não está totalmente domesticada, tendo sido frequente a ocorrência de problemas relacionados às sementes que apresentam germinação irregular e perda do poder germinativo após alguns meses de armazenamento.

Da mesma forma que em outras oleaginosas, diversos micro-organismos patogênicos responsáveis pela redução do poder germinativo também são encontrados em sementes de pinhão manso, como demonstrado por Neves et al. (2009a) e GoldFARB et al. (2010). Para CASTELlAni et al. (1996), muitos fungos afetam a germinação das sementes e podem ser transmitidos à progênie resultante, podendo se estabelecer no campo de cultivo e causar redução na qualidade e produtividade das culturas.

Diversos trabalhos já demonstraram a eficácia de fungicidas no tratamento de sementes em muitas culturas. Todavia, são incipientes os estudos relacionados à avaliação da qualidade sanitária e fisiológica de sementes de pinhão manso, assim como o registro de patógenos associados às sementes desta espécie.
Diante do exposto, objetivou-se a avaliar a eficiência dos fungicidas Carboxin + Thiram e Carbendazin + Thiram, em diferentes doses, na sanidade de sementes e seu efeito sobre o vigor de plântulas.

Os experimentos foram conduzidos no Laboratório de Fitopatologia e em casa-de-vegetação, na Universidade Federal da Grande Dourados - UFGD, no Município de Dourados, MS.

O delineamento experimental para ambos os ensaios foi inteiramente casualizado com 7 tratamentos, constando de 10 repetições para o ensaio de sanidade de sementes e 5 repetições para o ensaio sobre o vigor de plântulas.

As sementes de pinhão manso foram selecionadas de acordo com o seu peso, sendo utilizadas aquelas com peso entre 0,62 e $0,68 \mathrm{~g}$. Posteriormente, foram dividas em sete lotes de aproximadamente $500 \mathrm{~g}$. Depois da classificação, as sementes foram submetidas aos tratamentos: Carboxin + Thiram nas doses de 350, 450 e $550 \mathrm{~mL}$ e Carbendazin + Thiram nas doses de 200, 300 e $400 \mathrm{~mL}$ para cada $100 \mathrm{~kg}$ de sementes, e o tratamento controle onde foi utilizada apenas água destilada. As sementes foram colocadas em sacos plásticos, onde receberam os tratamentos, sendo a homogeneização realizada manualmente, por um período de 1 minuto, com movimentos constantes.

No ensaio de laboratório foi realizado o teste de sanidade de sementes, utilizando-se o método do papel filtro modificado com 2,4D (NEERGAARD, 1977; BRASIL, 2009), com adaptações devido o tamanho das sementes. Para cada tratamento, 120 sementes foram distribuídas em 10 gerbox, contendo três folhas de papel filtro, pré-umedecidas em solução do herbicida 2,4-D a $0,01 \%$. Posteriormente, foram incubadas por um período de sete dias, a temperatura de $22 \pm 2^{\circ} \mathrm{C}$, com fotoperíodo de 12 horas. A avaliação do controle dos fungos foi realizada com auxílio de microscópio.

Devido à elevada incidência e crescimento micelial de Fusarium sp. sobre as sementes, apresentandose em níveis diferenciados conforme os tratamentos a que foram submetidas, atribuíram-se notas às sementes, por meio da escala de 0 a 5 , em que $0=$ ausência do patógeno, $1=$ crescimento do patógeno ocupando entre 1 a $20 \%$ da área da semente, $2=20$ a $40 \%, 3=40$ a $60 \%, 4=60$ a $80 \%$ e $5=$ acima de $80 \%$ da semente tomada pelo fungo.

Para o ensaio de casa-de-vegetação, analisaramse o vigor das plântulas por meio da emergência a campo (EC), o índice de velocidade de emergência (IVE) e a altura de plantas (AP). Foram utilizadas como unidades experimentais bandejas medindo 37 $\mathrm{cm}$ de largura por 52 de comprimento, preenchidas com $10 \mathrm{dm}^{3}$ de solo peneirado, do tipo Latossolo Vermelho Distroférrico. A semeadura foi realizada manualmente com 30 sementes por parcela, alocadas a $3 \mathrm{~cm}$ de profundidade, dispostas sempre na mesma posição. Posteriormente à instalação do ensaio, o 
solo foi irrigado, mantendo-se um turno de rega de dois dias, de modo a manter a umidade do solo em $60 \%$ da capacidade de campo.

Para determinação da EC, considerou-se como semente emergida aquela que demonstrou sua aptidão em produzir uma planta normal sob condições de campo (BRASIL, 2009), sendo os resultados expressos em porcentagem de plantas normais. Para o IVE foram efetuadas contagens diárias a partir da primeira semente emergida até sua estabilização, e calculada pela fórmula proposta por MAGUIRE (1962). Aos 45 dias após a semeadura, com auxílio de régua graduada, foram mensuradas da base ao ápice todas as plantas emergidas na parcela.

Os dados obtidos foram submetidos à análise de variância com auxílio do programa Sistemas para Análises Estatísticas e Genéticas - SAEG, sendo que para o ensaio de laboratório os dados foram transformados em arcsen da $\sqrt{ } \mathrm{x} / 100$, e as médias comparadas por meio do teste SNK a $5 \%$ de significância. Foi calculada, também, a correlação linear entre a incidência fúngica e a emergência a campo.

A micoflora das sementes de pinhão manso, verificada no presente estudo, foi constituída por Aspergillus sp., Penicillium sp., Fusarium sp., Phomopsis sp. e Rhizopus sp. Fungos usualmente encontrados em sementes de outras culturas. Tanto a presença dos gêneros Aspergillus e Penicillium, considerados fungos de armazenamento, quanto de Fusarium e Phomopsis podem causar severos danos às sementes.

Os resultados apresentados na Tabela 1 evidenciam que todos os fungicidas reduziram a incidência fúngica, exceto Carbendazin + Thiram na dose de $200 \mathrm{~mL}$ que se comportou de maneira semelhante à testemunha. O tratamento com Carboxin + Thiram na dose de $550 \mathrm{~mL}$ sobressaiu-se em eficiência no controle dos fungos associados às sementes. Verifica-se que a utilização deste tratamento, quando comparado à testemunha, reduziu a incidência dos patógenos Aspergillus sp., Penicillium sp., Rhizopus sp., Fusarium sp. e Phomopsis sp., em 91,3; 99,1; 87,7; 67,5 e $49,3 \%$, respectivamente.
Os tratamentos com o fungicida Carboxin + Thiram proporcionaram melhor controle dos patógenos, exceto para Phomopsis sp., comparado a Carbendazin + Thiram, independente da dose testada.

Fusarium sp. foi o patógeno com maior percentual de incidência sobre as sementes de pinhão manso. Este fungo também foi relatado por GOLDFARB et al. (2010) como um dos gêneros mais encontrados em sementes desta cultura. Neves et al. (2009a) enfatizaram, ainda, que a incidência do fungo ocorre tanto em sementes desinfestadas, quanto naquelas não desinfestadas. A utilização do fungicida Carbendazin + Thiram, independente das doses testadas, não reduziu de modo efetivo a incidência deste patógeno. O controle mais eficaz foi alcançado com o uso de Carboxin + Thiram na maior dose, sendo superior aos demais tratamentos, sem, no entanto, erradicar o fungo das sementes. Corroborando com os resultados, relata-se que o tratamento em sementes de paineira (SIlva et al., 2003) e de pau-brasil (Lisboa-PAdulla et al., 2009) também não eliminaram totalmente a incidência do fungo. A dificuldade no controle deste patógeno pode estar associada a sua localização, pois ele pode se desenvolver interna e externamente nas sementes.

O patógeno com maior percentual de controle em relação à testemunha foi Penicillium sp., onde constatou-se um controle de $74,3 \%$ para Carbendazin + Thiram na dose de $200 \mathrm{~mL}$ e 99,1\% para Carboxin + Thiram na dose de $550 \mathrm{~mL}$, respectivamente. Enfatizaseque as doses testadas de Carboxin + Thiram foram significativamente superiores aos demais tratamentos, sem, no entanto, diferirem entre si quanto à incidência do fungo. Com a utilização de Carbendazin + Thiram, observou-se que o aumento na dose do produto melhorou sua eficiência. Comportamento contrário foi verificado para Aspergillus sp., onde o fungicida Carbendazin + Thiram proporcionou controle semelhante do patógeno, independente da dose utilizada. Enquanto que, para Carboxin + Thiram, nota-se uma dose dependência, ou seja, maior controle do fungo conforme se aumenta a dose do produto.

Tabela 1 - Incidência (\%) fúngica em sementes de pinhão manso submetidas ao tratamento com Carboxin + Thiram e Carbendazin + Thiram em diferentes dosagens. Dourados, MS, 2010.

\begin{tabular}{lccccc}
\hline Tratamentos (dose/100 kg de & \multicolumn{4}{c}{ Incidência dos fungos (\%) } \\
\cline { 2 - 6 } sementes) & Aspergillus sp. & Penicillium sp. & Fusarium sp. & Phomopsis sp. & Rhizopus sp. \\
\hline Carboxin + Thiram $550 \mathrm{~mL}$ & $8,3 \mathrm{a}$ & $0,8 \mathrm{a}$ & $32,5 \mathrm{a}$ & $31,7 \mathrm{a}$ & $10,8 \mathrm{a}$ \\
Carboxin + Thiram $450 \mathrm{~mL}$ & $13,3 \mathrm{~b}$ & $4,2 \mathrm{a}$ & $42,5 \mathrm{~b}$ & $50,8 \mathrm{~b}$ & $15,0 \mathrm{a}$ \\
Carboxin + Thiram $350 \mathrm{~mL}$ & $26,7 \mathrm{c}$ & $3,3 \mathrm{a}$ & $50,0 \mathrm{c}$ & $45,8 \mathrm{~b}$ & $21,7 \mathrm{~b}$ \\
Carbendazin + Thiram $400 \mathrm{~mL}$ & $50,0 \mathrm{~d}$ & $11,7 \mathrm{~b}$ & $77,5 \mathrm{~d}$ & $36,7 \mathrm{a}$ & $34,2 \mathrm{c}$ \\
Carbendazin + Thiram $300 \mathrm{~mL}$ & $53,3 \mathrm{~d}$ & $16,7 \mathrm{c}$ & $85,0 \mathrm{de}$ & $45,0 \mathrm{~b}$ & $36,7 \mathrm{c}$ \\
Carbendazin + Thiram $200 \mathrm{~mL}$ & $58,3 \mathrm{~d}$ & $22,5 \mathrm{~d}$ & $93,3 \mathrm{ef}$ & $52,5 \mathrm{~b}$ & $50,8 \mathrm{~d}$ \\
\hline Testemunha & $95,8 \mathrm{e}$ & $87,5 \mathrm{e}$ & $100,0 \mathrm{f}$ & $62,5 \mathrm{c}$ & $87,5 \mathrm{e}$ \\
\hline CV $(\%)$ & 8,54 & 12,16 & 5,73 & 7,97 & 10,80 \\
\hline
\end{tabular}

${ }^{*}$ Médias seguidas pela mesma letra não diferem entre si pelo teste SNK a 5 \% de probabilidade. 
O melhor controle de Phomopsis sp. foi obtido para os fungicidas nas doses mais elevadas, embora a doses intermediárias e inferiores tenham resultado em certo grau de controle do patógeno. Contra Rhizopus sp., foi verificada maior eficiência de controle com as doses de 450 e $550 \mathrm{~mL}$ de Carboxin + Thiram, com superioridade sobre os demais tratamentos. Este produto, na dose de $350 \mathrm{~mL}$, obteve percentual de controle intermediário, sendo superior aos tratamentos utilizando Carbendazin + Thiram que, todavia, apresentaram resultados superiores à testemunha.

Pela diversidade de fungos encontrados nas sementes de pinhão-manso, torna-se necessário estabelecer estratégias para se manter a boa qualidade sanitária das sementes (Neves et al., 2009a). O tratamento químico das sementes pode ser uma estratégia, apresentando resultado satisfatório, como demonstrado no presente estudo, onde ambos os fungicidas utilizados proporcionaram redução do percentual de incidência dos patógenos, com destaque para Carboxin + Thiram. Desta forma, pode-se afirmar que a melhora na eficiência dos produtos é dependente da cobertura de aplicação, dificilmente conseguida em toda a semente devido ao seu tamanho e principalmente a sua rugosidade.

Os níveis de infestação provocado por Fusarium sp. nas sementes apresentaram certas variações em relação aos resultados da incidência, principalmente, nos tratamentos com Carbendazin + Thiram. Verificou-se, por meio das notas, que todos os tratamentos com este produto reduziram a infestação do patógeno, quando comparado à testemunha (Fig. 1), restringindo desta forma o crescimento do fungo sobre o tegumento das sementes de pinhão manso.

O fungicida Carbendazin + Thiram reduziu a infestação do patógeno nas sementes, não sendo verificadas diferenças do tratamento nas doses de 300 e $400 \mathrm{~mL}$, quando comparado a Carboxin + Thiram na dose de $350 \mathrm{~mL}$. Todavia, os menores níveis de infestação foram observados nas doses de 450 e 550 $\mathrm{mL}$ de Carboxin + Thiram.

Com relação ao ensaio de vigor de plântulas, o resultado da análise de variância indicou efeito significativo do tratamento de sementes para as variáveis EC e IVE. A variável AP não diferiu estatisticamente para nenhum dos tratamentos (Tabela 2).

Os resultados do teste de EC revelaram eficiência de todos os tratamentos na melhora do vigor das sementes de pinhão manso. Foi observado aumento na porcentagem de emergência das plântulas, que variaram de 48,9 a $97,4 \%$, cujas sementes receberam os tratamentos Carboxin + Thiram e Carbendazin + Thiram, em todas as doses testadas, sendo significativamente superiores à testemunha. Embora seja

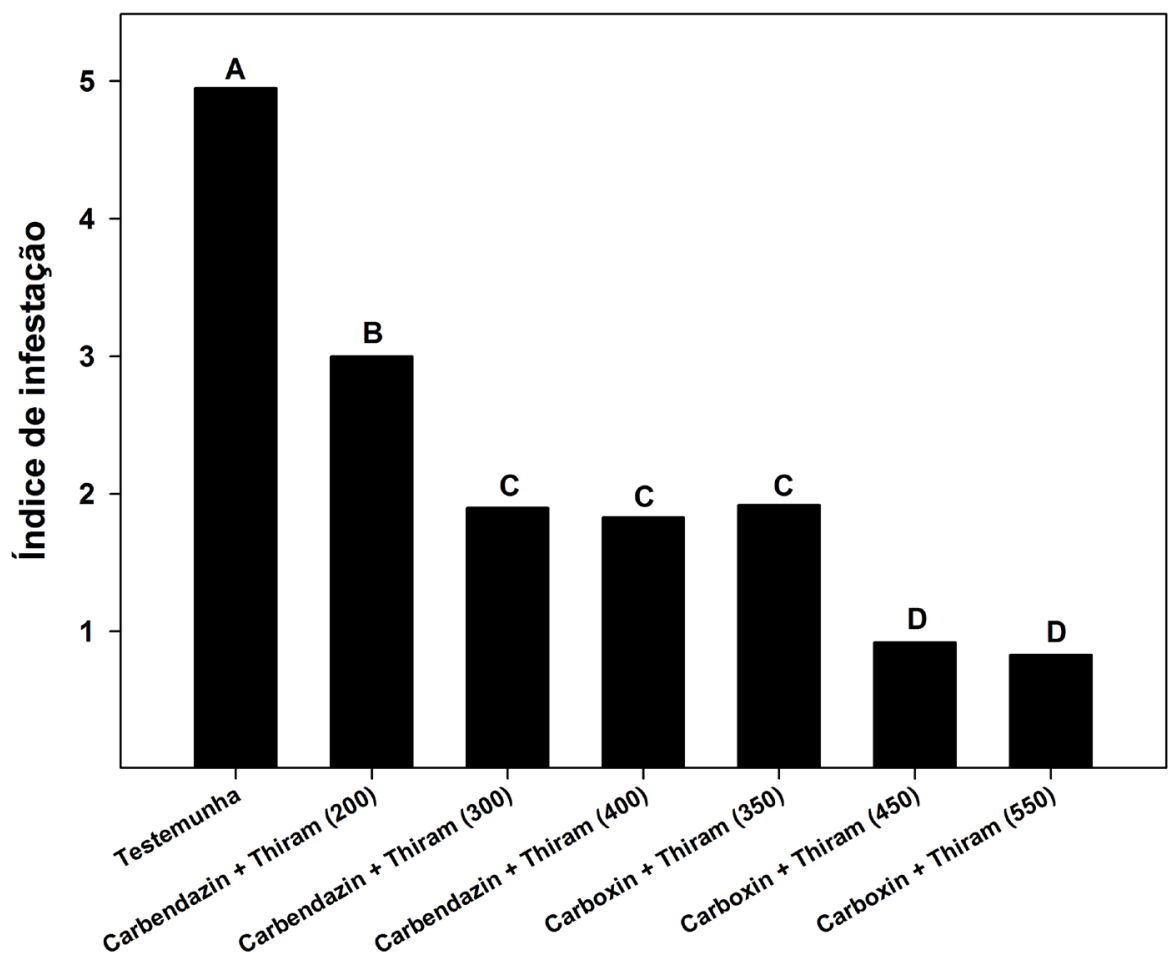

Fig. 1 - Índice de infestação de sementes de pinhão manso por Fusarium sp. sob diferentes doses de Carbendazin + Thiram (200, 300 e $\left.400 \mathrm{~mL} 100 \mathrm{~kg} \mathrm{sementes}^{-1}\right)$ e Carboxin + Thiram (350, 450 e $550 \mathrm{~mL} 100 \mathrm{~kg}$ sementes $\left.^{-1}\right)$. $\left(0=\right.$ ausência $^{2}$ do patógeno, 1 = crescimento do patógeno ocupando entre 1 a $20 \%$ da área da semente, $2=20$ a $40 \%, 3=40$ a $60 \%, 4=$ 60 a $80 \%$ e 5 = acima de $80 \%$ da semente tomada pelo fungo). Médias seguidas pela mesma letra não diferem entre si pelo teste SNK a $5 \%$ de probabilidade. Dourados-MS, 2010. 
relatado este incremento na quantidade de plântulas emergidas, nenhum dos tratamentos proporcionou valores de EC superior a 50\%, estando aquém dos valores verificados por GOLDFARB et al. (2010), que relataram média de $63,2 \%$ de germinação, e por HeLLER (1996), 62\% de germinação em média, com sementes armazenadas durante cinco meses em condições não controladas. Porém, superiores aqueles observados por Neves et al. (2009b) (35,3\%). Vale salientar que não foi observado fitotoxidez dos fungicidas, independente das doses testadas.

Em trabalhos sobre emergência de plântulas em função do peso das sementes, SEVERINo et al. (2006) verificaram porcentagens superiores de emergência de plântulas para as sementes com peso semelhante às utilizadas no experimento, sendo relatado valores que variaram de 74 a $84 \%$. Entretanto, a variação na porcentagem de plântulas normais, observada pelos autores, foi ampla, variando de 55 a $84 \%$. Esse fato pode estar associado à desuniformidade na maturação dos frutos de pinhão manso, que pode resultar na colheita de frutos em diferentes estádios de maturação, colocando em um mesmo lote sementes maduras e imaturas que, consequentemente, terão seu desempenho e qualidade fisiológica afetados. Nesse aspecto, AlbuQuerque et al. (2008) enfatizaram a necessidade de se conhecer os parâmetros que permitam detectar a maturidade fisiológica da cultura, correlacionando-a com características da planta, dos frutos e sementes.

A emergência das plântulas iniciou-se a partir do quinto dia após a semeadura (DAS) e estendeu- se até o décimo sétimo dia, com um "pico" entre o sétimo e décimo segundo. Devido ao período de emergência estender-se dessa forma, justificam-se os baixos valores registrados para IVE. NUNES et al. (2009), estudando a morfologia de sementes de pinhão manso, observaram que o tempo médio do processo germinativo com desenvolvimento da plântula variam de 15 a 30 dias. Enquanto que HELLER (1996) relatou, em condições ideais de umidade, germinação das sementes de pinhão manso aos 10 DAS. Os tratamentos com Carboxin + Thiram na dose de $550 \mathrm{~mL}$ e Carbendazin + Thiram nas doses de 400 e $300 \mathrm{~mL}$ aumentaram a velocidade de emergência das sementes quando comparadas à testemunha, sem, no entanto, diferirem dos demais tratamentos. SEVERINo et al. (2006) também observaram baixos valores de IVE, sendo relatado índices entre 1,28 a 1,69. Dessa forma, pode-se sugerir que o fato da cultura não apresentar um pico de emergência em um curto intervalo de tempo seja uma característica inerente da própria espécie.

As sementes de pinhão manso, analisadas na pesquisa, apresentaram percentual de emergência inferior aos resultados de HelLer (1996) e SEVERINO et al. (2006). Observaram-se que os tratamentos não eliminaram totalmente os fungos patogênicos, sendo verificadas altas porcentagens de incidência nas sementes, fato que pode explicar essas diferenças. Constata-se, na Tabela3, que a micoflora presentenas sementes foi inversamente proporcional à emergência a campo, aspecto comprovado pelos valores negativos obtidos para os coeficientes de correlação.

Tabela 2 - Percentual de emergência a campo (EC), índice de velocidade de emergência (IVE) e altura de plantas (AP) de pinhão manso submetido a diferentes tratamentos de sementes. Dourados, MS, 2010.

\begin{tabular}{|c|c|c|c|}
\hline \multirow{2}{*}{ Tratamentos (dose/100 kg de sementes) } & \multicolumn{3}{|c|}{ Variáveis analisadas } \\
\hline & $\mathrm{EC}(\%)$ & IVE & $\mathrm{AP}(\mathrm{cm})^{\mathrm{ns}}$ \\
\hline Carboxin + Thiram $550 \mathrm{~mL}$ & $42,7 \mathrm{a}$ & $1,34 \mathrm{a}$ & 17,54 \\
\hline Carboxin + Thiram $450 \mathrm{~mL}$ & $34,7 \mathrm{a}$ & $1,13 \mathrm{ab}$ & 18,75 \\
\hline Carboxin + Thiram $350 \mathrm{~mL}$ & $44,7 \mathrm{a}$ & $1,16 \mathrm{ab}$ & 18,63 \\
\hline Carbendazin + Thiram $400 \mathrm{~mL}$ & $46,0 \mathrm{a}$ & $1,38 \mathrm{a}$ & 17,01 \\
\hline Carbendazin + Thiram $300 \mathrm{~mL}$ & $39,3 \mathrm{a}$ & $1,29 \mathrm{a}$ & 17,54 \\
\hline Carbendazin + Thiram $200 \mathrm{~mL}$ & $37,3 \mathrm{a}$ & $1,07 \mathrm{ab}$ & 16,22 \\
\hline Testemunha & $23,3 \mathrm{~b}$ & $0,73 \mathrm{~b}$ & 17,20 \\
\hline $\mathrm{CV}(\%)$ & 11,70 & 13,55 & 4,72 \\
\hline
\end{tabular}

${ }^{*}$ Médias seguidas pela mesma letra não diferem entre si pelo teste SNK a 5 \% de probabilidade. NS: Não significativo.

Tabela 3 - Coeficientes de correlação entre os atributos emergência a campo e a incidência fúngica em sementes de pinhão manso. Dourados, MS, 2010.

\begin{tabular}{llllll}
\hline & Aspergillus sp. & Penicillium sp. & Fusarium sp. & Phomopsis sp. & Rhizopus sp. \\
\hline EC & $-0,6336$ & $-0,8625^{*}$ & $-0,4797$ & $-0,8585^{*}$ & $-0,7588$
\end{tabular}

*Coeficiente de correlação significativa. 
As maiores correlações da emergência a campo $x$ incidência do fungo nas sementes foram obtidas pelos fungos Penicillium sp. e Phomopsis sp. De acordo com Goulart et al. (1995), Phomopsis sp. está entre os principais fungos que mais afetam a germinação das sementes. Para Oliveira et al. (1997) e Silva; Silva (2000), a incidência de Penicillium sp. eAspergillus sp. interferem negativamente o desempenho fisiológico das sementes.

Apesar de ser o fungo mais prevalente nas sementes de pinhão manso, Fusarium sp. apresentou a menor relação com a redução de plântulas emergidas. Entretanto, estudando fungos em sementes de mamona, planta pertencente à família das Euforbiáceas, a mesma do pinhão manso, Lima et al. (1997) afirmaram que este patógeno é um dos responsáveis por ocasionar podridão nas sementes e afetar o seu poder germinativo. Enquanto que VON PINHO et al. (1995) atribuíram o baixo poder de germinação das sementes à alta e conjunta incidência de patógenos, destacando entre eles Fusarium sp., Penicillium sp. e Aspergillus sp.

Pode-se concluir que Fusarium sp. é o patógeno mais incidente nas sementes de pinhão manso, todavia, correlações significativas com a baixa emergência são atribuídas à presença de Penicillium sp. e Phomopsis sp. Sementes de pinhão manso tratadas com Carboxin + Thiram apresentam melhor qualidade sanitária e, independente do fungicida utilizado, a prática do tratamento de sementeresulta em aumento no percentual de emergência a campo da cultura do pinhão manso.

\section{AGRADECIMENTOS}

À CAPES pela concessão da bolsa, aos engenheiros agrônomos Lenita Aparecida e Anderson Bergamin pela colaboração e a Luis Bello pelas sementes de pinhão manso.

\section{REFERÊNCIAS}

ALBUQUERQUE, F.A.; LUCENA, A.M.A.; OLIVEIRA, M.I.P.; ANDRADE, J.R.; BELTRÃO, N.E.M.; ARRIEL, N.H.C. Aspectos fisiológicos de sementes de pinhão manso oriundas de frutos colhidos em diferentes estádios de maturação. Campina Grande: Ministério da Agricultura Pecuária e Abastecimento, 2008. 5p. (Circular Técnica 124).

ARRUDA, F.P.; BELTRÃO, N.E.M.; ANDRADE, A.P.; PEREIRA, W.E.; SEVERINO, L.S. Cultivo do pinhão manso (Jatrofa curcas L.) como alternativa para o semi-árido Nordestino. Revista Brasileira de Oleaginosas e Fibrosas, Campina Grande, v.8, n.1, p.789-799, 2004.
BRASIL. Ministério da Agricultura, Pecuária e Abastecimento. Secretaria de Defesa Agropecuária. Regras para Análise de Sementes. Brasília: MAPA/ACS, 2009. 399p.

CASTELLANI. E.D.; SILVA, A.; BARRETO, M.; AGUIAR, I.B. Influência do tratamento químico na população de fungos e na germinação de sementes de Bauhinia variegata L. var variegata. Revista Brasileira de Sementes, v.18, n.1, p.41-44, 1996.

GOLDFARB, M.; DUARTE, M.E.M.; MATA, M.E.R.M.C.; NASCIMENTO, L.C.; BRITO, N.M.; SOUTO, F.M. Incidência de fungos e qualidade fisiológica de sementes de pinhão manso (Jatropha curcas L.) após o armazenamento criogênico. Revista Biotemas, v.23, n.1, p.19-26, 2010.

GOULART, A.C.P.; PAIVA, F.A.; ANDRADE, P.J.M. Qualidade sanitária de sementes de soja (Glycine max (L.) Merrill) produzidas no Mato Grosso do Sul. Revista Brasileira de Sementes, v.17, n.1, p.42-46, 1995.

HELLER, J. Physic nut. Jatrofa curcas L. Promoting the conservation and use of underutilized and neglected crops. 1. Rome: Institute of Plant Genetics and Crop Plant Research, Gatersleben/International Plant Genetic Resources Institute, 1996. 66p.

LIMA, E.F.; BATISTA, F.A.S.; SANTOS, J.W. Fungos causadores de tombamento transportados e transmitidos pela semente da mamoneira. Pesquisa Agropecuária Brasileira, v.32, n.9, p.915-918, 1997.

LISBOA-PADULLA, T.; MORAES, M.H.D.; MENTEN, J.O.M.; BARBEDO, C. Tratamento de sementes de pau-brasil com fungicidas: efeito na incidência de fungos, germinação e transmissão de fungos pelas sementes. Summa Phytopathologica, v.35, n.2, p.148-150, 2009.

MAGUIRE, J.D. Speeds of germination-aid and evaluation for seedling emergence and vigor. Crop Science, v.2, n.2, p.176-177, 1962.

NEERGAARD, P. Seed pathology. London: The Mac Millan Press, 1977. v.2. 1191p.

NEVES, J.M.G.; SILVA, H.P.; BRANDÃO JUNIOR, D.S.; MARTINS, E.R.; NUNES, U.R. Padronização do teste de germinação para sementes de pinhão manso. Revista Caatinga, v.22, n.4, p.76-80, 2009b.

NUNES, C.F.; SANTOS, D.N.; PASQUAL, M.; VALENTE, T.C.T. Morfologia externa de frutos, sementes e plântulas de pinhão manso. Pesquisa Agropecuária Brasileira, v.44, n.2, p.207-210, 2009.

OLIVEIRA, J.A.; VIEIRA, M.G.G.C.; VON PINHO, E.V.R.; CARVALHO, M.L.M. Comportamento de sementes de milho tratadas com fungicidas antes e após o armazenamento convencional. Revista Brasileira de Sementes, v.19, n.2, p.207-212, 1997. 
PIENIZ, T; SILVA, T.R.B. Aplicação de aminoácidos no tratamento de sementes de pinhão manso. Cultivando $o$ Saber, v.1, n.1, p.80-86, 2008.

SATURNINO, H.M.; PACHECO, D.D.; KAKIDA, J.; TOMINAGA, N.; GONÇALVES, N.P. Cultura do pinhão-manso (Jatropha curcas L.). Informe Agropecuário, v.26, n.229, p.44-78, 2005.

SEVERINO, L.S.; LIMA, R.L.S.; BELTRÃO, N.E.M. Germinação e crescimento inicial de plântulas de pinhão manso em função do peso da semente. Campina Grande: Ministério da Agricultura Pecuária e Abastecimento, 2006. 4p. (Comunicado Técnico 309).

SILVA, M.A.D.; SILVA, W.R. Comportamento de fungos e de sementes de feijoeiro durante o teste de envelhecimento artificial. Pesquisa Agropecuária Brasileira, v.35, n.3, p.599-608, 2000.
SILVA, R.T.V.; HOMECHIN, M.; FONSECA, E.P.; SANTIAGO, D.C. Tratamento de sementes e armazenamento na sanidade de sementes de paineira (Chorisia speciosa St. Hil). Semina: Ciências Agrárias, v.24, n.2, p.255-260, 2003.

TEIXEIRA, L.C. Potencialidades de oleaginosas para produção de biodiesel. Informe Agropecuário, v.26, n.229, p.18-27, 2005.

VON PINHO, E.V.R.; CAVARIANI, C.; ALEXANDRE, A.D.; MENTEN, O.M.; MORAES, M.H.D. Efeitos do tratamento fungicida sobre qualidade sanitária e fisiológica de sementes de milho (Zea mays, L.). Revista Brasileira de Sementes, v.17, n.1, p.23-28, 1995.

Recebido em 29/9/10

Aceito em 30/11/11 